\title{
Papers
}

\section{Migraine and stroke in young women: case-control study}

\author{
C L Chang, Michael Donaghy, Neil Poulter, and World Health Organisation Collaborative Study of \\ Cardiovascular Disease and Steroid Hormone Contraception
}

\begin{abstract}
Objective To investigate the association between migraine and ischaemic or haemorrhagic stroke in young women.

Design Hospital based case-control study.

Setting Five European centres participating in the World Health Organisation Collaborative Study of Cardiovascular Disease and Steroid Hormone Contraception.
\end{abstract}

Subjects 291 women aged 20-44 years with ischaemic, haemorrhagic, or unclassified arterial stroke compared with 736 age and hospital matched controls.

Intervention Questionnaire.

Main outcome measure Self reported history of headaches.

Results Adjusted odds ratios associated with a personal history of migraine were 1.78 (95\%

confidence intervals, 1.14 to 2.77 ), 3.54 (1.30 to 9.61), and 1.10 (0.63 to 1.94) for all stroke, ischaemic stroke, and haemorrhagic stroke respectively. Odds ratios for ischaemic stroke were similar for classical migraine (with aura) (3.81, 1.26 to 11.5$)$ and simple migraine (without aura) $(2.97,0.66$ to 13.5$)$. A family history of migraine, irrespective of personal history, was also associated with increased odds ratios, not only for ischaemic stroke but also haemorrhagic stroke. In migrainous women, coexistent use of oral contraceptives or a history of high blood pressure or smoking had greater than multiplicative effects on the odds ratios for ischaemic stroke associated with migraine alone. Change in the frequency or type of migraine on using oral contraceptives did not predict subsequent stroke. Between 20\% and $40 \%$ of strokes in women with migraine seemed to develop directly from a migraine attack.

Conclusions Migraine in women of childbearing age significantly increases the risk of ischaemic but not haemorrhagic stroke. The coexistence of oral contraceptive use, high blood pressure, or smoking seems to exert a greater than multiplicative effect on the risk of ischaemic stroke associated with migraine.

\section{Introduction}

Migraine has been reported as a risk factor for ischaemic stroke in men ${ }^{12}$ and premenopausal women..$^{2-5}$ Two reports have shown that classical migraine (with aura) poses a higher risk than simple migraine (without aura). ${ }^{4}$ Migraine seems to be a background risk factor for stroke. Migraine also acts as an acute precipitant of stroke because some patients have a stroke during a migraine attack (migrainous stroke).$^{7-9}$ The relative occurrence of these two types of stroke related to migraine is unknown.

The notion that oral contraceptive use and migraine might interact in predisposing to stroke was proposed by Bickerstaff. ${ }^{10}$ A case-control study showed a substantially increased risk of ischaemic stroke in women who had migraines and who used oral contraceptives. ${ }^{4}$ Bickerstaff cited examples of changed patterns of migraine heralding a stroke in women starting oral contraceptives. ${ }^{10} \mathrm{He}$, and later others, advised that women should stop taking oral contraceptives if their migraine changed from simple (without aura) to classical (with aura). ${ }^{10}$ To date, however, no formal studies have examined whether a change in migraine type on starting oral contraceptives is a predictor of stroke in women.

Oral contraceptives are known to be an independent risk factor for ischaemic and haemorrhagic strokes, particularly in patients who smoke, are aged over 35 , or who have a history of hypertension. ${ }^{12-14}$ This risk is lower in women who use low dose $(<50 \mu \mathrm{g}$ oestrogen $)$ rather than high dose $(\geqslant 50 \mu \mathrm{g})$ contraceptives. ${ }^{13}$ The effect of migraine among women taking either low or high dose oral contraceptives upon the risk of developing ischaemic or haemorrhagic stroke was previously unestablished.

This study on the influence of migraine on ischaemic and haemorrhagic stroke was affiliated to an ongoing case-control study of oral contraceptive use and cardiovascular diseases.$^{15}$ It investigated the extent to which simple or classical migraine predispose to ischaemic stroke, haemorrhagic stroke, and all stroke (combined ischaemic, haemorrhagic, and unclassified stroke); the interaction between migraine and oral contraceptives, hypertensive history, or smoking in determining the risk of stroke; whether any such risk is still present for low dose contraceptives; whether a change in the type of migraine-for example, from simple to classical-heralds stroke in women taking oral contraceptives; and the proportion of strokes in women who have migraines that develop directly out of a migraine attack.

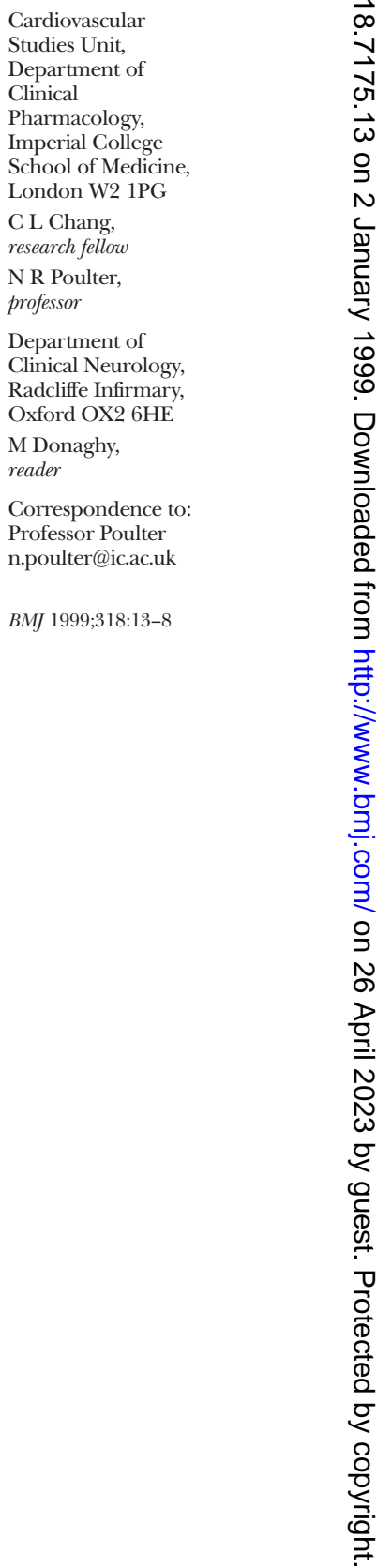




\section{Subjects and methods}

This study was carried out in eight cities (Oxford, Berlin, Hodmezovasarhely, Mako, Szeged, Szentes, Belgrade, and Ljubljana) from the five European centres participating in the WHO collaborative study of cardiovascular disease and steroid hormone contraceptives, which was a hospital based case-control study in 17 countries. A detailed description of the methods used in the WHO study has been published previously. ${ }^{15}$

In brief, each collaborating centre recruited women aged 20-44 years who had had a stroke, acute myocardial infarction, or venous thromboembolic disease. Each case was matched with up to three controls from a variable number of participating hospitals. Women were considered to be eligible for the present study if they were aged 20-44 years, they had been admitted to a participating hospital between June 1990 and January 1993 (January 1994 in one centre) inclusive, and they had a discharge diagnosis of stroke. Women were excluded if they had: (a) had a transient ischaemic attack (an event lasting < 24 hours); (b) had died within 24 hours of admission; (c) had a history of stroke, deep vein thrombosis, pulmonary embolism, acute myocardial infarction, or natural or surgical menopause; $(d)$ had a recent history (within 6 weeks) of pregnancy; or (e) had a major illness causing prolonged bed rest or surgery. Verbal informed consent was obtained from all cases and controls. This was recorded in the study questionnaire.

\section{Case definition}

A monitoring system was set up in each centre to identify all eligible cases of stroke. These cases were classified into one of seven types of stroke after a review of their medical history and the results of examination and investigations - namely, intracerebral (including intraventricular, intraparenchymal, and intracerebellar), subarachnoid haemorrhagic stroke, undifferentiated haemorrhagic stroke, ischaemic stroke with or without a possible cardiac source of embolus, unclassified (unknown type), and venous (or some other non-stroke diagnosis classed as "other"). The criteria used to diagnose ischaemic, haemorrhagic, and unclassified strokes have been fully described previously. ${ }^{13} 14$

\section{Controls and interview}

Up to three hospital based controls, matched by 5 year age bands (20-24, 25-29, 30-34, 35-39, 40-44) and time of admission, were recruited for each case as previously described. ${ }^{13}{ }^{15}$ Controls were subject to the same exclusion criteria as cases. They had to have been admitted to the same hospital as the case, with one of 27 diagnoses considered to have no association with use of oral contraceptives. ${ }^{15}$ All cases and controls were interviewed using a standardised questionnaire. The questionnaire included information on self reported details of medical and reproductive history, use of drugs, family history of premature stroke and heart attack, or both, smoking habit, use of contraceptives, use of alcohol and coffee, educational attainment, and social class. In five European countries a supplementary questionnaire was given to all cases of stroke and their controls. This contained additional information on the nature and frequency of past and current headaches, accompanying aura, family history of migraine, changes in the frequency and characteristics of headache associated with use of oral contraceptives, and whether headache with migrainous features had occurred within 3 days before the onset of stroke. The definition of simple migraine, based on the International Headache Society's criteria, ${ }^{16}$ was defined as a self reported history of a recent severe headache lasting for more than 4 hours but less than 3 days, which occurred on one or both sides of the head, and which was associated with feeling sick and finding loud noises or bright lights unpleasant, or both. Simple migraine symptoms accompanied by an initial aura consisting of visual disturbance or abnormalities of speech, skin sensation, or muscle power, were defined as classical migraine. A family history of migraine was considered positive if subjects reported that one or more of either of their parents, siblings, or children had had migraine.

\section{Statistical analysis}

Odds ratios for stroke associated with a history of migraine compared with women who had not had migraine were computed by conditional logistic regression and adjusted for confounding variables defined using standard criteria. ${ }^{17}$ Stroke (all strokes, ischaemic stroke, or haemorrhagic stroke) was fitted as the dependent variable, and known risk factors and migraine status were independent variables. Data were analysed with SAS and EGRET. ${ }^{18}$

\section{Results}

In the five European centres, the supplementary questionnaire was completed by 291 of 309 (94.2\%) women who had had a stroke (86 ischaemic, 187 haemorrhagic, 18 unclassified) and 736 matched controls (220, 472 , and 44 respectively for the three types of stroke). An average of 2.2, 1.8, 2.7, 2.8, and 2.4 controls were recruited per case in the United Kingdom, Germany, Hungary, Slovenia, and Yugoslavia respectively. More than half of the cases were from Slovenia and Yugoslavia and about two thirds of all strokes were haemorrhagic in type, with an overall ratio of haemorrhagic to ischaemic stroke of 2.2:1. Of 187 cases of haemorrhagic stroke, 150 (80.2\%) were subarachnoid.

Among cases of stroke and their controls, 25.4\% $(74 / 291)$ and $13.0 \%(96 / 736)$ respectively gave a history of migraine. Table 1 shows various characteristics of cases and their matched controls by migraine status. Both cases and controls with a history of migraine were significantly more likely to report a history of blood pressure problems in pregnancy $(\mathrm{P}<0.05)$ or a family history of migraine $(\mathrm{P}<0.001)$ than those without such a history. Irrespective of migraine history, cases were more likely than controls to report a history of: hypertension during and outside pregnancy (at any time before the stroke (cases) or before hospital admission (controls)); diabetes; heavy smoking ( $\geqslant 10$ cigarettes per day); heavy alcohol intake $(\geqslant 14$ units per week); and a family history of premature stroke $(<60$ years) and migraine. Cases were also more likely than controls to be current users of oral contraceptives. Of those women who had had migraine, approximately $70 \%$ of both cases $(51 / 74)$ 
and controls (69/96) had the classical type. About 25\% of cases $(74 / 291)$ reported a history of migraine and $26 \%(\mathrm{n}=75)$ gave a family history of migraine (data not shown). Among controls, 13\% (96/736) reported a personal history of migraine and $12 \%(\mathrm{n}=87)$ a family history of migraine (data not shown). A history of migraine was reported more frequently among women who had had an ischaemic stroke (26/86, 30\%) than among those who had had a haemorrhagic stroke (39/ $187,21 \%$ ) (data not shown).

Women with a personal history of migraine had significantly increased odds ratios for ischaemic stroke, but not haemorrhagic stroke, than those without migraine (table 2). Odds ratios associated with both simple and classical migraine were higher for ischaemic than for haemorrhagic stroke. Odds ratios for both ischaemic and haemorrhagic stroke were significantly increased among women with a family history of migraine. After adjustment for a personal history of migraine this association was reduced, but odds ratios remained significantly increased: 2.07 (95\% confidence interval 1.31 to 3.26 ), 3.62 (1.37 to 9.58 ), and 2.22 (1.26 to 3.90) for all stroke, ischaemic stroke, and haemorrhagic stroke respectively. In addition, odds ratios for ischaemic and haemorrhagic stroke associated with a family history of migraine in those without a personal history of migraine were also increased (table 3 ).

Table 3 also shows, among women with and without a history of migraine, the odds ratios for ischaemic and haemorrhagic stroke associated with: use of oral contraceptives; a history of high blood pressure excluding hypertension in pregnancy; a history of hypertension in pregnancy; and smoking. The coexistence of each of these factors has a greater than multiplicative effect on the odds ratios for ischaemic stroke associated with a history of migraine, although the apparent synergy was only statistically significant for smoking $(\mathrm{P}=0.05)$. Among women with no history of migraine, the odds ratio for ischaemic stroke associated with the use of low dose oral contraceptives was close to unity (1.19, 0.33 to 4.29$)$. Odds ratios for both ischaemic and haemorrhagic stroke associated with use of oral contraceptives were lower among women using low dose $(<50 \mu$ g oestrogen) oral contraceptives than among women using high dose ( $\geqslant 50 \mu \mathrm{g}$ oestrogen) oral contraceptives, irrespective of migraine status. Furthermore, compared with women who did not smoke, did not use oral contraceptives, and did not report a history of migraine, the odds ratio for ischaemic stroke associated with use of oral contraceptives in current smokers with a history of migraine based on nine cases and two controls was 34.4 (3.27 to 361). Odds ratios for haemorrhagic stroke among migrainous women were only significantly increased in those who had a history of high blood pressure and in those who were current smokers. These increased odds ratios were further increased, but not significantly so, by use of oral contraceptives in these subgroups of women (data not shown).

Table 4 shows, among women who had ever used oral contraceptives, the frequency distribution of changes in frequency of headache and type of migraine among cases and controls during use of oral contraceptives. More than $80 \%$ of migrainous women
Table 1 Characteristics of cases and controls by migraine status. Values are numbers (percentages) of women unless stated otherwise

\begin{tabular}{|c|c|c|c|c|}
\hline \multirow[b]{2}{*}{ Variable } & \multicolumn{2}{|c|}{ No migraine } & \multicolumn{2}{|c|}{ Migraine } \\
\hline & $\begin{array}{c}\text { Cases } \\
(n=217)\end{array}$ & $\begin{array}{l}\text { Controls } \\
(n=640)\end{array}$ & $\begin{array}{l}\text { Cases } \\
(\mathrm{n}=74)\end{array}$ & $\begin{array}{c}\text { Controls } \\
(n=96)\end{array}$ \\
\hline Age (years) mean (SD) & $36.3(5.9)$ & $36.0(5.8)$ & $36.1(5.6)$ & $35.7(6.2)$ \\
\hline Body mass index $\left(\mathrm{kg} / \mathrm{m}^{2}\right)$ mean (SD) & $24.0(4.3)$ & $24.4(4.4)$ & $24.3(4.4)$ & $24.7(3.3)$ \\
\hline No of live births (mean (SD)) & $1.6(1.3)$ & $1.5(1.0)$ & $1.7(1.0)$ & $1.7(0.9)$ \\
\hline Current oral contraceptive use & $47(21.8)^{*}$ & $100(15.7) \dagger$ & $18(24.3)$ & $20(20.8)$ \\
\hline \multicolumn{5}{|l|}{ Medical history: } \\
\hline High blood pressure & $53(24.4)$ & $40(6.3)$ & $21(28.8)^{*}$ & $11(11.5)$ \\
\hline Diabetes & $5(2.3)$ & $5(0.8)$ & $5(6.8)$ & 0 \\
\hline Hypertension in pregnancy & $32(14.8)$ & $60(9.4)$ & $20(27.0)$ & $16(16.7)$ \\
\hline Abnormal blood lipids & $3(1.4)$ & $6(1.0)$ & $1(1.4)$ & $1(1.1)$ \\
\hline \multicolumn{5}{|l|}{ Smokingł: } \\
\hline Never & $77(35.5)$ & $304(47.9)$ & $19(25.7)$ & $43(45.7)$ \\
\hline Past & $24(11.1)$ & $63(9.9)$ & $4(5.4)$ & $8(8.5)$ \\
\hline$<10$ cigarettes per day & $17(7.8)$ & $51(8.0)$ & $6(8.1)$ & $9(9.6)$ \\
\hline$\geqslant 10$ cigarettes per day & $99(45.6)$ & $217(34.2)$ & $45(60.8)$ & $34(36.2)$ \\
\hline \multicolumn{5}{|l|}{ Alcohol: } \\
\hline Never & $49(22.6)$ & $173(27.1) \dagger$ & $21(28.4)$ & $20(21.1)^{\star}$ \\
\hline Occasional & $152(70.0)$ & $450(70.6)$ & $50(67.6)$ & 74 (77.9) \\
\hline$\geqslant 14$ units per week & $16(7.4)$ & $15(2.3)$ & $3(4.0)$ & $1(1.0)$ \\
\hline \multicolumn{5}{|l|}{ Migraine: } \\
\hline Simple & - & - & $23(31.1)$ & $27(28.1)$ \\
\hline Classical & - & - & $51(68.9)$ & 69 (71.9) \\
\hline \multicolumn{5}{|l|}{ Family history: } \\
\hline Stroke & $8(3.7)$ & $18(2.8)$ & $7(9.5)$ & 0 \\
\hline Migraine§ & $34(15.7)$ & $46(7.2)$ & $41(55.4)$ & $41(43.2)^{*}$ \\
\hline
\end{tabular}

*One case or control with missing data. †Two controls with missing data. ‡Seven controls with missing data. §Including siblings, parents, and grandparents.

Table 2 Adjusted odds ratios* (95\% confidence intervals) for types of stroke associated with personal or family history of migraine

\begin{tabular}{|c|c|c|c|c|c|c|}
\hline \multirow[b]{2}{*}{ Variable } & \multicolumn{2}{|c|}{ Ischaemic stroke $\dagger$} & \multicolumn{2}{|c|}{ Haemorrhagic strokeł } & \multicolumn{2}{|c|}{ All stroke§ } \\
\hline & $\begin{array}{c}\text { Odds ratios } \\
(95 \% \mathrm{Cl})\end{array}$ & $\begin{array}{l}\text { No of } \\
\text { cases/ } \\
\text { controls }\end{array}$ & $\begin{array}{l}\text { Odds ratios } \\
(95 \% \mathrm{CI})\end{array}$ & $\begin{array}{l}\text { No of } \\
\text { cases/ } \\
\text { controls }\end{array}$ & $\begin{array}{l}\text { Odds ratios } \\
(95 \% \mathrm{CI})\end{array}$ & $\begin{array}{l}\text { No of } \\
\text { cases/ } \\
\text { controls }\end{array}$ \\
\hline Simple & $\begin{array}{c}2.97 \\
(0.66 \text { to } 13.5)\end{array}$ & $7 / 9$ & $\begin{array}{c}1.84 \\
(0.77 \text { to } 4.39)\end{array}$ & $14 / 15$ & $\begin{array}{c}2.25 \\
\text { (1.10 to } 4.63)\end{array}$ & $21 / 23$ \\
\hline Classical & $\begin{array}{c}3.81 \\
(1.26 \text { to } 11.5) \\
\end{array}$ & 19/17 & $\begin{array}{c}0.86 \\
(0.44 \text { to } 1.67) \\
\end{array}$ & $24 / 46$ & $\begin{array}{c}1.62 \\
(0.98 \text { to } 2.67) \\
\end{array}$ & $50 / 65$ \\
\hline Migraine (total) & $\begin{array}{c}3.54 \\
(1.30 \text { to } 9.61)\end{array}$ & $26 / 26$ & $\begin{array}{c}1.10 \\
(0.63 \text { to } 1.94)\end{array}$ & $38 / 61$ & $\begin{array}{c}1.78 \\
\text { (1.14 to } 2.77 \text { ) } \\
\end{array}$ & $71 / 88$ \\
\hline $\begin{array}{l}\text { Family history } \\
\text { of migraine§ }\end{array}$ & $\begin{array}{c}4.99 \\
(2.03 \text { to } 12.3)\end{array}$ & $23 / 26$ & $\begin{array}{c}2.30 \\
(1.35 \text { to } 3.90)\end{array}$ & $41 / 50$ & $\begin{array}{c}2.55 \\
(1.67 \text { to } 3.90)\end{array}$ & $65 / 76$ \\
\hline
\end{tabular}

*Reference group: women with no personal history of migraine.

†Adjusted for high blood pressure, education, smoking categories, family history of migraine (not in §), alcohol consumption, and social class.

$\ddagger$ Adjusted for high blood pressure, body mass index, smoking categories, and family history of migraine (not in §).

§lschaemic, haemorrhagic, and unclassified stroke.

who used oral contraceptives had not experienced any change in frequency of headache or type of migraine in relation to using the oral contraceptive. Compared with controls, there was no excess of conversion from simple to classical migraine after starting oral contraceptives in the women who had had a stroke.

In those women with a prior history of migraine, between $67 \%$ and $73 \%$ of strokes were preceded by headache within the 3 days before the stroke compared with $24-31 \%$ of women with no history of migraine (table 5). This difference was not simply caused by headache as a symptom of haemorrhagic stroke since the effect was equally strong for ischaemic stroke. For most of the migrainous women who had had an ischaemic stroke, the headache during the 3 days before the stroke was associated with other features of migraine. This headache stopped before the 
Table 3 Adjusted odds ratios (95\% confidence intervals) of ischaemic and haemorrhagic stroke in relation to risk factors

\begin{tabular}{|c|c|c|c|c|c|c|c|c|}
\hline \multirow[b]{3}{*}{ Risk factors } & \multicolumn{4}{|c|}{ Ischaemic stroke } & \multicolumn{4}{|c|}{ Haemorrhagic stroke } \\
\hline & \multicolumn{2}{|c|}{ No Migraine } & \multicolumn{2}{|c|}{ Migraine } & \multicolumn{2}{|c|}{ No Migraine } & \multicolumn{2}{|c|}{ Migraine } \\
\hline & $\begin{array}{l}\text { Odds ratios } \\
(95 \% \mathrm{CI})\end{array}$ & $\begin{array}{l}\text { No of cases/ } \\
\text { controls }\end{array}$ & $\begin{array}{l}\text { Odds ratios } \\
(95 \% \mathrm{Cl})\end{array}$ & $\begin{array}{l}\text { No of cases/ } \\
\text { controls }\end{array}$ & $\begin{array}{l}\text { Odds ratios } \\
(95 \% \mathrm{Cl})\end{array}$ & $\begin{array}{l}\text { No of cases/ } \\
\text { controls }\end{array}$ & $\begin{array}{l}\text { Odds ratios } \\
(95 \% \mathrm{Cl})\end{array}$ & $\begin{array}{l}\text { No of cases/ } \\
\text { controls }\end{array}$ \\
\hline No oral contraceptives & 1.00 & $41 / 146^{*}$ & 2.27 (0.69 to 7.47$)$ & $16 / 23$ & 1.00 & $114 / 329 \dagger$ & 1.13 (0.60 to 2.12$)$ & $30 / 45$ \\
\hline Oral contraceptives: & 2.76 (1.01 to 7.55$)$ & $19 / 42$ & $16.9(2.72$ to 106$)$ & $10 / 3$ & $1.10(0.55$ to 2.19$)$ & $20 / 49$ & $1.10(0.40$ to 2.97$)$ & $8 / 16$ \\
\hline Low dose $(<50 \mu \mathrm{g})$ & $1.19(0.33$ to 4.29$)$ & $10 / 28$ & $6.59(0.79$ to 54.8$)$ & $4 / 3$ & $0.76(0.32$ to 1.81$)$ & $12 / 40$ & $0.52(0.13$ to 2.01$)$ & $4 / 13$ \\
\hline High dose $(\geqslant 50 \mu \mathrm{g})$ & 7.95 (1.94 to 32.6$)$ & 9/14 & CC & $6 / 0$ & 1.95 (0.66 to 5.79$)$ & $8 / 9$ & $2.66(0.46$ to 15.3$)$ & $3 / 3$ \\
\hline High blood pressure & 6.35 (2.19 to 18.5$)$ & $15 / 15$ & CC & $6 / 1$ & 6.24 (3.09 to 12.6) & $33 / 23$ & $3.29(1.14$ to 9.46$)$ & $11 / 8$ \\
\hline No hypertension in pregnancy & 1.00 & $49 / 165^{*}$ & 2.14 (0.70 to 6.56$)$ & 19/22 & 1.00 & $117 / 350 \dagger$ & 0.99 (0.52 to 1.89$)$ & $26 / 51$ \\
\hline Hypertension in pregnancy & 1.77 (0.48 to 6.47$)$ & $11 / 23$ & 13.5 (2.37 to 77.2$)$ & $7 / 4$ & $1.57(0.74$ to 3.31$)$ & $18 / 30$ & $2.22(0.80$ to 6.13$)$ & $12 / 10$ \\
\hline Non-smoker & 1.00 & $33 / 1159$ & 1.56 (0.41 to 5.85$)$ & $7 / 15$ & 1.00 & $59 / 219^{\star *}$ & $0.75(0.31$ to 1.79$)$ & $10 / 34$ \\
\hline Smoker & 0.82 (0.36 to 1.89$)$ & $27 / 73$ & 7.39 (2.14 to 25.5$)$ & $19 / 11$ & 1.80 (1.15 to 2.82$)$ & $76 / 161$ & 2.66 (1.29 to 5.49$)$ & $28 / 27$ \\
\hline No family history of migraine & 1.00 & $53 / 171^{*}$ & 2.27 (0.69 to 7.50$)$ & $10 / 17$ & 1.00 & $114 / 357 \dagger$ & 1.22 (0.60 to 2.50$)$ & $18 / 34$ \\
\hline $\begin{array}{l}\text { With family history of } \\
\text { migrainet† }\end{array}$ & 1.89 (0.45 to 7.87$)$ & $7 / 17$ & 17.3 (4.45 to 67.2$)$ & $16 / 9$ & 2.44 (1.20 to 4.94$)$ & $21 / 23$ & 2.31 (1.15 to 4.64$)$ & $20 / 27$ \\
\hline
\end{tabular}

$\mathrm{CC}=$ Cannot be calculated. *Adjusted for high blood pressure, education, smoking categories, family history of migraine (not in $† \dagger)$, alcohol consumption, and social class; $†$ Adjusted for high blood pressure, family history of migraine (not in t†), smoking categories, and body mass index categories; łAdjusted for education, smoking categories, family history of migraine, alcohol consumption, and social class; §Adjusted for family history of migraine, smoking categories, and body mass index categories; ๆAdjusted for high blood pressure, education, family history of migraine, alcohol consumption, and social class; **Adjusted for high blood pressure, family history of migraine, and body mass index categories.

Table 4 Frequency distribution of change in frequency of headache and type of migraine among subjects who had ever used oral contraceptives. Values are numbers (percentages) of women unless stated otherwise

\begin{tabular}{lcccccc} 
& $\begin{array}{c}\text { Ischaemic } \\
\text { stroke } \\
(\mathbf{n = 1 9 )}\end{array}$ & $\begin{array}{c}\text { Controls } \\
\mathbf{( n = 1 7 )}\end{array}$ & $\begin{array}{c}\text { Haemorrhagic } \\
\text { stroke }(\mathbf{n}=\mathbf{2 4 )}\end{array}$ & $\begin{array}{c}\text { Controls } \\
(\mathbf{n}=\mathbf{4 5})\end{array}$ & $\begin{array}{c}\text { All stroke* } \\
\mathbf{( n = 4 8 )}\end{array}$ & $\begin{array}{c}\text { Controls } \\
\mathbf{( n = 6 3 )}\end{array}$ \\
\hline Changes in frequency of headache after oral contraceptive use \\
\hline No change & $14(82.3)$ & $15(88.2)$ & $21(87.5)$ & $39(86.7)$ & $37(80.4)$ & $55(87.3)$ \\
\hline Decreased & $1(5.9)$ & $2(11.8)$ & 0 & 0 & $1(2.2)$ & $2(3.2)$ \\
\hline Increased & $2(11.8)$ & 0 & $3(12.5)$ & $6(13.3)$ & $8(17.4)$ & $6(9.5)$ \\
\hline Unknown & 2 & 0 & 0 & 0 & 2 & 0 \\
\hline Changes in type of migraine after oral contraceptive use & & & \\
\hline No change & $16(84.2)$ & $16(94.2)$ & $22(91.6)$ & $37(82.2)$ & $42(87.5)$ & $54(85.7)$ \\
\hline Simple to classical & $3(15.8)$ & 0 & $1(4.2)$ & $8(17.8)$ & $5(10.4)$ & $8(12.7)$ \\
\hline Classical to simple & 0 & $1(5.9)$ & $1(4.2)$ & 0 & $1(2.1)$ & $1(1.6)$ \\
\hline
\end{tabular}

*Including unspecified stroke.

symptoms of ischaemic stroke in $16 \%(3 / 19)$ of migrainous women and 22\% (4/18) of women with no history of migraine. These results suggest that $40 \%$ of ischaemic strokes in women who have migraine develop directly from a migraine attack.

\section{Discussion}

In this large case-control study of women aged 20-44 years, based in five European countries, one quarter of women who had had a stroke reported a personal history of migraine and one quarter reported a family history of migraine. A personal history of migraine was associated with a significant increase in adjusted odds ratios for ischaemic stroke $(3.54,95 \%$ confidence interval 1.30 to 9.61$)$ but not for haemorrhagic stroke (1.10, 0.63 to 1.94). Odds ratios for ischaemic stroke associated with classical migraine were nonsignificantly greater than for simple migraine (3.81, 1.26 to 11.5 , and $2.97,0.66$ to 13.5 respectively).

The effect of several other risk factors, including current oral contraceptive use, showed a more than multiplicative effect on odds ratios for ischaemic stroke associated with migraine. An early case-control study did not find that migraine increased the risk of either thrombotic or haemorrhagic stroke in women taking oral contraceptives. ${ }^{19}$ A subsequent case-control study on a relatively small number of cases reported an association between migraine and ischaemic stroke, particularly with classical migraine, but this study did not examine the association with haemorrhagic stroke. ${ }^{4}$ This same study found an additionally increased risk of ischaemic stroke in migrainous women who also used oral contraceptives containing high doses of oestrogen $(\geqslant 50 \mu \mathrm{g})$, or who smoked heavily. ${ }^{4}$ In the present study the odds ratios for both ischaemic and haemorrhagic stroke associated with or without migraine were higher in women who used high dose oral contraceptives than in those who used low dose oral contraceptives (table 3 ).

One further study of undifferentiated stroke in men and women aged under 45 pointed to a probable risk from classical, but not simple, migraine; the interaction with use of oral contraceptives in the women could not be calculated. ${ }^{5}$ Migraine was associated with undifferentiated stroke and ischaemic stroke in a cohort of male physicians, but the risk of haemorrhagic stroke could not be evaluated and there was no differentiation between effects of simple and classical migraine. ${ }^{20}$

Table 5 Frequency distribution of stroke cases immediately preceded by headache by usual type of migraine

\begin{tabular}{|c|c|c|c|c|c|c|}
\hline \multirow[b]{2}{*}{ Previous migraine status all cases $(n=291)$} & \multicolumn{2}{|c|}{ Ischaemic stroke } & \multicolumn{2}{|c|}{ Haemorrhagic stroke } & \multicolumn{2}{|c|}{ All stroke* } \\
\hline & $\begin{array}{c}\text { Non-migrainous } \\
(n=60) \dagger\end{array}$ & $\begin{array}{l}\text { Migrainous } \\
(\mathrm{n}=26)\end{array}$ & $\begin{array}{l}\text { Non-migrainous } \\
\quad(n=148)\end{array}$ & $\begin{array}{l}\text { Migrainous } \\
(\mathrm{n}=39)\end{array}$ & $\begin{array}{l}\text { Non-migrainous } \\
(n=217) \dagger\end{array}$ & $\begin{array}{l}\text { Migrainous } \\
(n=74)\end{array}$ \\
\hline Headache in 3 days before stroke & $18(30.5)$ & $19(73.1)$ & $35(23.6)$ & $26(66.7)$ & $56(25.9)$ & $52(70.3)$ \\
\hline Headache with aura in 3 days before stroke & $5(8.5)$ & $4(15.4)$ & $2(1.4)$ & $3(7.7)$ & $7(3.2)$ & $8(10.8)$ \\
\hline Headache stopped before stroke & $4(6.8)$ & $3(11.5)$ & $9(6.1)$ & $6(15.4)$ & $15(6.9)$ & $10(7.4)$ \\
\hline
\end{tabular}

${ }^{*}$ Ischaemic, haemorrhagic, and unclassified stroke.

†One subject with missing values in headache group. 
No previous study has evaluated the effect of any change in migraine type on risk of stroke after use of oral contraceptives. Despite Bickerstaff's accounts of a change in migraine type heralding a stroke, we did not find compelling supportive evidence. ${ }^{10}$ Although about one in six cases of ischaemic stroke did convert from simple to classical migraine after starting oral contraceptives, and none of the controls for these cases changed migraine type in this way, the rates of conversion from simple to classical migraine were essentially the same among all cases of stroke and their controls (difference of $2.3 \%, 95 \%$ confidence interval $-9.7 \%$ to $14.3 \%$ ) (table 4).

A family history of migraine was associated with a significant increase in risk of ischaemic and haemorrhagic stroke and remained significantly increased after adjustment for a personal history of migraine. Furthermore, odds ratios were increased among women with a family history but no personal history of migraine (table 3). An explanation other than chance for this surprising finding (particularly the increased risk of haemorrhagic stroke) is not clear. It is possible that it reflects a form of reporting bias. Between the relevant two groups of controls there were no differences in use of oral contraceptives, smoking habit, body mass index, or age.

The apparent interaction between migraine history and high blood pressure (during or excluding pregnancy) on odds ratios for ischaemic stroke has not previously been reported. One study did, however, report an apparent but non-significant interaction between migraine and either use of oral contraceptives or smoking habit. ${ }^{4}$ The data presented here suggest that women who have migraine should be advised strongly not to smoke, and that their blood pressure should be carefully monitored and controlled. A large proportion of women who use oral contraceptives also smoke. ${ }^{13}{ }^{14}$ Hence the finding of an odds ratio of 34.4 (3.3 to 361) for ischaemic stroke among migrainous women who use oral contraceptives and smoke is of considerable concern, even though the rate of cases of stroke fulfilling the eligibility criteria of the study (estimated from one of the European collaborative centres to be 5.5 per 100000 woman years) was relatively low. ${ }^{14}$

The potential shortcomings of case-control studies-for example, their propensity for various biases-are well established and have been addressed previously in the context of the WHO study, ${ }^{15}{ }^{21}$ as have other potential limitations of the WHO collaborative study for each of the diseases studied. ${ }^{13} 142122$ Biased recall of migraine type among cases of stroke could have occurred. The likelihood of this potential bias, however, may have been restricted because the interviewers, cases, and controls were blinded to the hypothesis being tested, and also because the questionnaire focused on headaches, and migraine was not actually mentioned until the end of the questionnaire. By means of strict standardised diagnostic criteria and the concurrent recruitment of cases, we achieved a more accurate classification of cases than that found in most previous studies.

\section{Conclusions}

Overall, the risk of ischaemic stroke among European women of childbearing age was increased more than threefold if they were migrainous, but no such increase
Key messages

- A personal history of migraine was associated with increased risk of ischaemic but not haemorrhagic stroke

- Coexistence of risk factors-use of oral contraceptives, high blood pressure, or smoking had more than multiplicative effects on odds ratios for ischaemic stroke associated with migraine alone

- A family history of migraine, irrespective of a personal migraine history, was associated with increased risk of ischaemic and haemorrhagic stroke

- Up to $40 \%$ of strokes in migrainous women develop directly out of a migraine attack-so called migrainous strokes

- A change in type or frequency of migraine with use of oral contraceptives did not predict subsequent stroke

was apparent for haemorrhagic stroke. In addition to conferring a background risk of stroke, up to $40 \%$ of strokes in migrainous women seem to develop directly out of a migraine attack - a so called migrainous stroke. Our data do not permit us to subdivide cases of migrainous stroke into stroke with the clinical features of migraine, in which the structural lesion is unrelated to the clinical features of the migraine attack, and migraine induced stroke in which the neurological deficit is identical to migraine symptoms of previous attacks. ${ }^{23}$ The greater than multiplicative effect of other coexistent risk factors-namely, use of oral contraceptives, smoking, high blood pressure- on the risk of stroke among migrainous women was statistically significant only for smoking, but remains worrisome, and women should be advised accordingly. The finding of an increased odds ratio of both ischaemic and haemorrhagic stroke associated with a family history of migraine independent of a personal history of migraine merits further investigation.

We thank Sandra Johnson for help in the preparation of the manuscript, Professor MG Marmot for continued advice and support throughout the study, and Professor M Harrison who developed the algorithm used for classifying strokes and advised on the classification of specific stroke cases.

Contributors: CLC managed the data collection and performed the analyses on the dataset of the WHO study. MD designed the migraine questionnaire. NRP was the co-principal investigator and coordinator for the study; he was jointly responsible for the design of the WHO study, commented extensively on the manuscript, and will act as guarantor for the study. All three authors contributed to all sections of the manuscript and reviewed drafts of the manuscript.

Funding: This study was funded by the United Nations Development Programme/United Nations Populations Fund/ World Health Organisation/World Bank Special Programme of Research, Development, and Research Training in Human Reproduction, and the National Institutes of Health Contraceptive and Reproductive Evaluation Branch (contract National Institute of Child Health and Human Development NO1-HD-02914). Supplementary financial support for local coordination was provided by some national medical research councils.

Competing interest: None.

1 Buring JE. Low-dose oral contraceptives and stroke. New Engl J Med 1996;335:53-4. 
2 Merikangas KR, Fenton BT, Cheng SH, Stolar MJ, Risch N. Association between migraine and stroke in a large-scale epidemiological study of the United States. Arch Neurol 1997;54:362-8.

3 Henrich JB, Horwitz RI. A controlled study of ischaemic stroke risk in migraine patients. J Clin Epidemiol 1989;42:773-80.

4 Tzourio C, Tehindrazanarivelo A, Iglésias S, Alperovich A, Chedru F, d'Anglejan-Chatillon J, et al. Case-control study of migraine and risk of ischaemic stroke in young women. BMJ 1995;310:830-3.

5 Carolei A, Marini C, De Matteis G. History of migraine and risk of cerebral ischaemia in young adults. Lancet 1996;347:1503-6

6 Marini C, Carolei A, Roberts RS, Prencipe M, Gandolfo C, Inzitari D et al, and the National Research Council Study Group. Focal cerebral ischaemia in young adults: a collaborative case-control study. Neuroepidemiology 1993;12:70-1.

7 Welch KMA, Levine SR. Migraine-related stroke in the context of the International Headache Society classification of head pain. Arch Neurol 1900;47:458-62.

8 Bogousslavsky J, Regli F, Van Melle G, Payot M, Uske A. Migraine stroke. Neurology 1988;38:223-7.

9 Rothrock JF, Walicke P, Swenson MR, Lyden PD, Logan WR. Migrainous stroke. Arch Neurol 1988;45:63-7.

10 Bickerstaff ER. Neurological complications of oral contraceptives. Oxford: Oxford University Press, 1975

11 Migraine and oral contraception. Drug Ther Bull 1987;25:95-6.

12 Petitti DB, Sidney S, Bernstein A, Wolf S, Quesenberry C, Ziel HK, et al. Stroke in users of low-dose oral contraceptives. New Engl J Med 1996;335:8-15.

13 World Health Organization Collaborative Study of Cardiovascular Disease and Steroid Hormone Contraception. Ischaemic stroke and combined oral contraceptives: results of an international multicentre, case-control study. Lancet 1996;348:498-510.
14 World Health Organization Collaborative Study of Cardiovascular Disease and Steroid Hormone Contraception. Haemorrhagic stroke, overall stroke risk, and combined oral contraceptives: results of an international, multicentre, case-control study. Lancet 1996;348:505-10.

15 World Health Organization Collaborative Study of Cardiovascular Disease and Steroid Hormone Contraception. A multinational study of cardiovascular disease and steroid hormone contraceptives: description and validation of methods. J Clin Epidemiol 1995;48:1513-47.

16 Classification and diagnostic criteria for headache disorders, cranial neuralgias and facial pain. Headache Classification Committee of the International Headache Society. Cephalagia 1988;8(suppl 7):1-96.

17 Maldonado G, Greenland S. Simulation study of confounder-selection strategies. Am J Epidemiol 1993;138:923-36.

18 Darney PD. The androgenicity of progestins. Am J Med 1995;98:104-10S.

19 Collaborative Group for the Study of Stroke in Young Women. Oral contraceptives and stroke in young women: associated risk factors. JAMA 1975;231:718-22.

20 Buring JE, Hebert R, Romero J, Kittross A, Cook N, Manson J, et al. Migraine and subsequent risk of stroke in the Physicians' Health Study. Arch Neurol 1995;52:129-34.

21 World Health Organization Collaborative Study of Cardiovascular Disease and Steroid Hormone Contraception. Venous thromboembolic disease and combined oral contraceptives: results of international multicentre case-control study. Lancet 1995;346:1575-82.

22 The World Health Organization Collaborative Study of Cardiovascular Disease and Steroid Hormone Contraception. Acute myocardial infarction and combined oral contraceptives: results of an international multicentre case-control study. Lancet 1997;349:1202-9.

23 Welch KMA. Relationship of stroke and migraine. Neurology 1994;44(suppl 7):533-6.

(Accepted 23 October 1998)

\section{Social class in childhood and general health in adulthood: questionnaire study of contribution of psychological attributes}

Hans Bosma, H Dike van de Mheen, Johan P Mackenbach

Erasmus University Rotterdam, Department of Public Health, PO Box $1738,3000 \mathrm{DR}$ Rotterdam,

Netherlands

Hans Bosma, senior researcher H Dike van de Mheen,

senior researcher

Johan P

Mackenbach,

professor

Correspondence to: Dr Bosma bosma@ mgz.fgg.eur.nl

BMJ 1999;318:18-22

\section{Abstract}

Objective To determine the contribution of psychological attributes (personality characteristics and coping styles) to the association between social class in childhood and adult health among men and women.

Design Partly retrospective, partly cross sectional study conducted in the framework of the Dutch GLOBE study.

Subjects Sample of general population from south east Netherlands consisting of 2174 men and women aged 25-74 years. Baseline self reported data from 1991 provided information on childhood and adult social class, psychological attributes, and general health.

Main outcome measure Self rated poor health. Results Independent of adult social class, low childhood social class was related to self rated poor health (odds ratio 1.67 (95\% confidence interval 1.02 to 2.75 ) for subjects whose fathers were unskilled manual workers versus subjects whose fathers were higher grade professionals). Subjects whose fathers were manual workers generally had more unfavourable personality profiles and more negative coping styles. External locus of control, neuroticism, and the absence of active problem focused coping explained about half of the association between childhood social class and self rated poor health. The findings were independent of adult social class and height.
Conclusions A higher prevalence of negative personality profiles and adverse coping styles in subjects who grew up in lower social classes explains part of the association between social class in childhood and adult health. This finding underlines the importance of psychological mechanisms in the examination of the negative effects of adverse socioeconomic conditions in childhood.

\section{Introduction}

There is now increasing evidence that differences in adult health are partly caused by socioeconomic factors during early life and upbringing. ${ }^{1-5}$ The causal mechanisms relating adverse socioeconomic conditions in childhood and poor health in adulthood have not yet been examined extensively. Biological mechanisms, such as hypertension and hypercholesterolaemia, have been suggested, ${ }^{6-8}$ and there is some evidence for mechanisms related to lifestyle, such as smoking and physical activity. ${ }^{3-12}$ With few exceptions the contribution of psychological attributes, such as personality factors and coping styles, has hardly been examined. ${ }^{10}{ }^{13} 14$ Psychological attributes are partially rooted in environmental conditions in childhood, (learning) experiences, and rearing styles. ${ }^{14-16}$ There is now also increasing evidence that psychological attributes influence health through behavioural mechanisms (for example, smoking) or direct physiological mechanisms, or both. ${ }^{17}$ Unhealthy personality factors and coping strategies may, therefore, be 